\title{
Vertical transposition of the horizontal recti (Knapp procedure) for the treatment of double elevator palsy: effectiveness and long-term stability
}

Department of

Ophthalmology,

University of Iowa

Hospitals and Clinics,

Iowa City, Iowa, 52242,

USA

J P Burke

J B Ruben

W E Scott

Correspondence to:

Dr W E Scott.

Accepted for publication 28 July 1992

John P Burke, James B Ruben, William E Scott

\begin{abstract}
Full tendon width vertical transposition (Knapp procedure) of the horizontal recti is an established treatment for double elevator palsy (DEP) but the long-term stability of the surgical results have not been well studied. We undertook a retrospective study to determine the overall effectiveness of the Knapp procedure, the postoperative stability of alignment, and the influence of prior inferior rectus muscle recession (IRc) on the magnitude of correction. Nineteen patients with DEP underwent a Knapp procedure. Eight were corrected to within $5^{\Delta}$ of orthophoria, six were undercorrected, and five were overcorrected by at least $5^{\Delta}$ after a mean follow-up of 3 years (to last visit or to further surgical intervention). The average vertical correction was $37 \cdot 5^{\Delta}$ in patients who underwent a prior IRc compared with $21 \cdot 1^{\Delta}$ in patients with no prior IRc $(p=<0 \cdot 0017)$. Over and undercorrections were more likely to occur in patients with prior IRc. Postoperative drift was towards increased effect in all patients. The seven patients with long-term (>36 months) follow-up demonstrated an increased magnitude of correction (average $=12 \cdot 6^{\triangle}$ ) over an average follow-up of 76 months. The Knapp procedure had an increasing effect over time but the amount of vertical correction did not correlate with the size of the preoperative vertical deviation and was less predictable when a prior IRc had been performed.
\end{abstract}

(Brf Ophthalmol 1992; 76: 734-737)

A monocular elevation deficiency may occur on a restrictive or paretic basis, and has an extensive differential diagnosis that includes both local, neuromuscular, and central nervous system aetiologies. ${ }^{12}$ A specific type of monocular elevation deficiency characterised by underaction of both elevators of one eye (the superior rectus and inferior oblique), was first described by White ${ }^{3}$ and was later termed 'double elevator palsy' (DEP) by Dunlap. ${ }^{4}$ It may be congenital or acquired, ${ }^{5}$ and is generally considered supranuclear in origin. ${ }^{26}$

Early surgical attempts to correct vertical misalignment from DEP employed either conventional vertical rectus muscle surgery ${ }^{3+}$ or partial vertical transpositions of the horizontal recti. $^{78}$ These efforts had limited success. Watson' reported effective treatment of DEP using a surgical technique initially developed and later described in a larger series by Knapp. ${ }^{10}$ He described complete transposition of the horizontal recti tendons to a position adjacent to the insertion of the superior rectus (Knapp procedure). This has become a standard treatment for DEP. Only patients with free forced ductions were included in Knapp's original series; however, evidence now suggests that long-standing hypotropia from a DEP may result in secondary contracture of the inferior rectus. ${ }^{611-1+}$ These patients frequently demonstrate restriction on forced duction testing and require recession of the inferior rectus in addition to a Knapp procedure.

Numerous studies have reported successful treatment of DEP with a Knapp procedure, ${ }^{169-111^{1315-18}}$ yet long-term stability of alignment has not been well documented. In this study, we analysed the long-term alignment, and the effect of prior inferior rectus recession (IRc) on the magnitude of the vertical correction following a Knapp procedure.

\section{Subjects and methods}

A computer data base retrieval system at the University of Iowa Pediatric Ophthalmology and Strabismus service was searched for all patients with congenital or acquired DEP who underwent a Knapp procedure between 1966 and 1990. A retrospective chart review was performed on all 21 patients. All had other causes for monocular limitation of elevation excluded; including thyroid eye disease, a history of orbital trauma, third nerve palsy, a past history of orbital inflammation, orbital tumour, or surgical recession or disinsertion of the superior rectus muscle.

All patients had pre and postoperative evaluations performed at the University of Iowa which included assessment of visual acuity, pupillary function, motility, slit-lamp, and ophthalmic examination. Fusional status was assessed using the Worth 4-dot test at distance and near, and using the Titmus stereoacuity test. Pre and postoperative motility measurements were obtained by prism cover testing while fixating in primary gaze at an accommodative target 6 metres away. Neutralising prisms were held in front of the eye with the DEP to measure the primary deviation. All patients had supraplacement of the medial and lateral recti to a position within $2 \mathrm{~mm}$ of the position described by Knapp (Fig 1). ${ }^{10}$ Short-term measurements were obtained 1 week postoperatively and the last measurements were those of the most recent clinic visit or the examination preceding any subsequent rectus muscle surgery.

Two patients were excluded from this study. The first patient had severe restriction noted at the time of Knapp surgery but no release of the 
Figure 1 Knapp

procedure. Illustration of the transposed tendon site for the medial rectus muscle $(M R M)$ and the lateral rectus muscle (LRM). (SRM - superior rectus muscle) of the left eye.

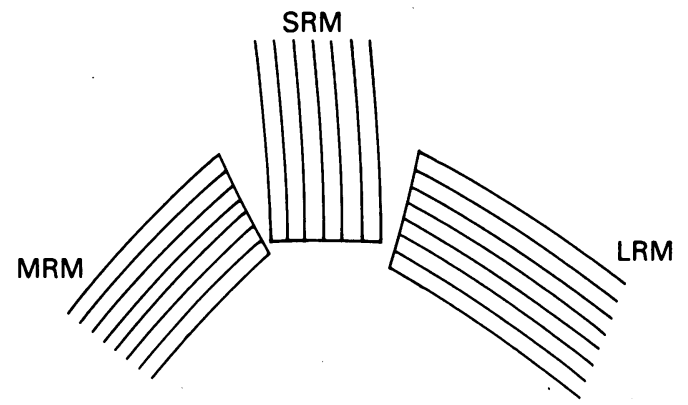

restriction was performed; consequently, no correction in primary position was noted postoperatively. The second patient had a superior rectus recession performed in the contralateral eye at the time of the Knapp procedure and was also noted to develop a dissociated vertical deviation in the eye with the DEP. This patient was excluded because concomitant vertical rectus surgery at the time of the Knapp procedure prevented accurate assessment of the magnitude of correction attributable to the transposition.

\section{Results}

Nineteen patients underwent a Knapp procedure, and were aged between 1 and 35 years at the time of surgery (mean $7 \cdot 6$ years). Seven patients had a history of prior extraocular muscle surgery. One patient had a superior rectus resection and medial rectus resection before the Knapp procedure. Six patients had a prior IRc in the eye that 3 to 6 months later underwent a Knapp procedure.

Prior to their Knapp procedure 17 patients had a manifest vertical deviation $\left(\geq 5^{\Delta}\right)$ in primary gaze. The largest deviation was $55^{\Delta}$ and the average deviation for all patients was $28 \cdot 2^{\Delta}$. The preoperative deviation measured immediately before the Knapp procedure averaged $30.5^{\Delta}$ for the six patients who underwent a prior IRc and $22 \cdot 8^{\Delta}$ in the 13 patients who did not. The other two patients had a latent vertical deviation in primary gaze and a hypotropia on elevation. Eleven patients preferred fixation with the unaffected eye and two patients alternated fixation. Five patients had evidence of preoperative fusion but required an abnormal head position to maintain fusion.

The follow-up for our 19 patients ranged from 6 to 144 months (mean $36 \cdot 2$ months). Seven

Table 1 Stability of alignment following the Knapp procedure for patients with $\geq 36$ months follow-up

\begin{tabular}{|c|c|c|c|c|c|}
\hline Case & $\begin{array}{l}\text { Pre-op } \\
\text { deviation } \\
(\triangle)\end{array}$ & $\begin{array}{l}\text { Short-term } \\
\text { post-op } \\
\text { deviation } \\
(\triangle)\end{array}$ & $\begin{array}{l}\text { Duration } \\
\text { of follow-up } \\
\text { (months) }\end{array}$ & $\begin{array}{l}\text { Long-term } \\
\text { post-op } \\
\text { deviation } \\
(\triangle)\end{array}$ & $\begin{array}{l}\text { Amount } \\
\text { post-op } \\
\text { drift } \\
(\triangle)\end{array}$ \\
\hline $\begin{array}{l}1 \\
2^{\star} \\
3 \\
4 \\
5 \\
6 \\
7\end{array}$ & $\begin{array}{l}35 \mathrm{LHT} \\
18 \mathrm{LHT} \\
20 \mathrm{LHT} \\
20 \mathrm{LHT} \\
30 \mathrm{RHT} \\
20 \mathrm{LHT} \\
25 \mathrm{LHT}\end{array}$ & $\begin{array}{r}14 \text { LHT } \\
2 \text { RHT } \\
20 \text { LHT } \\
4 \text { RHT } \\
2 \text { RHT } \\
2 \text { LHT } \\
12 \text { LHT }\end{array}$ & $\begin{array}{r}144 \\
96 \\
84 \\
36 \\
60 \\
55 \\
57\end{array}$ & $\begin{array}{l}4 \text { RHT } \\
28 \text { RHT } \\
5 \text { LHT } \\
10 \text { RHT } \\
3 \text { LHT } \\
4 \text { RHT } \\
\text { Ortho }\end{array}$ & $\begin{array}{r}18 \\
26 \\
15 \\
6 \\
5 \\
6 \\
12\end{array}$ \\
\hline \multicolumn{3}{|l|}{$\begin{array}{l}\text { Mean } \\
\text { Standard error }\end{array}$} & 76 & & $\begin{array}{r}12 \cdot 6 \\
2 \cdot 9\end{array}$ \\
\hline \multicolumn{6}{|c|}{$\begin{array}{l}t \text { test comparing drift values with null hypothesis of no drift } \\
\text { Degrees of freedom }=6 ; t=4.30 ; p=0.0051\end{array}$} \\
\hline
\end{tabular}

$\star$ Prior inferior rectus recession
Table 2 Effect of prior inferior rectus recession on the vertical correction from the Knapp procedure

\begin{tabular}{lcc}
\hline & $\begin{array}{l}\text { Amount corrected } \\
\text { No prior IRc }\end{array}$ & Prior IRc \\
\hline$n$ & 13 & 6 \\
Mean correction $(\triangle)$ & $21 \cdot 1$ & $37 \cdot 5$ \\
Standard error $(\triangle)$ & $2 \cdot 6$ & $3 \cdot 0$ \\
High $(\triangle)$ & $39 \cdot 0$ & $46 \cdot 0$ \\
Low $(\triangle)$ & $5 \cdot 0$ & $27 \cdot 0$ \\
Unpaired $t$ test between both groups: & \\
Degrees of freedom $=17 ; t=3 \cdot 72 ; \mathrm{p}=0 \cdot 017$ & \\
\hline
\end{tabular}

patients had postoperative follow-up greater than 36 months, and their average follow-up was 76 months (Table 1) (only one of these had a prior IRc). When the vertical deviation in primary position 1 week postoperatively was compared with that of the most recent follow-up visit all seven patients demonstrated an increased magnitude of vertical correction with time (average $12 \cdot 6^{\Delta}$, range $5^{\Delta}-26^{\Delta}$ ). A one sample $t$ test comparing the observed change 1 week postoperatively with that of the more recent visit, with a null hypothesis of no change, generated a $t$ value of $4.30(\mathrm{p}=0.0051)$ for a two-tailed distribution with 6 degrees of freedom. Postoperative drift was invariably towards increased effect from the surgery with time, but no consistent trend with regard to its timing was noted. Some patients drifted within the first few postoperative weeks; others up to several years later.

Table 2 shows the magnitude of vertical correction observed in the 19 patients who underwent a Knapp procedure. An unpaired $t$ test comparing the magnitude of correction achieved in the group of patients who underwent a prior IRc generates a $t$ value of $3.72(p=0.0017$ with 17 degrees of freedom).

Vertical alignment following the Knapp procedure is shown in Table 3. The success of vertical alignment was lower in patients who underwent a prior IRc in comparison to patients who did not. Eight patients were successfully corrected to within $5^{\Delta}$ of orthophoria, six were undercorrected and five were overcorrected by at least $5^{\Delta}$ at the last follow-up visit. Overcorrection occurred in $50 \%$ (3/6) of patients who underwent prior IRc and only in $15 \%(2 / 13)$ of the patients who had no prior IRc. The frequency of undercorrection was also higher in the patients who underwent prior IRc. Regression analysis revealed that the magnitude of vertical correction obtained by the Knapp procedure was not to the magnitude of preoperative deviation regardless of whether or not a prior IRc had been performed.

Table 3 Success of vertical alignment following Knapp procedure

\begin{tabular}{lll}
\hline & $\begin{array}{l}\text { Prior inferior } \\
\text { rectus recession }\end{array}$ & $\begin{array}{l}\text { No prior } \\
\text { inferior } \\
\text { rectus recession }\end{array}$ \\
\hline $\begin{array}{l}\text { Number of patients } \\
\text { undercorrected } \geq 5 \text { of } \\
\text { orthophoria }\end{array}$ & 2 & \\
$\begin{array}{c}\text { Number of patients } \\
\text { corrected to within 5 } \\
\text { of orthophoria }\end{array}$ & 1 & 8 \\
$\begin{array}{c}\text { Number of patients } \\
\text { overcorrected } \geq 5 \text { of } \\
\text { orthophoria }\end{array}$ & 3 & 2 \\
\begin{tabular}{c} 
Total number of patients \\
\hline
\end{tabular} & 6 & 13 \\
\hline
\end{tabular}


A significant $\left(\geq 10^{\triangleleft}\right)$ horizontal deviation was present in 11 patients at the time of their Knapp surgery (six patients were esotropic and five were exotropic). Five patients had horizontal rectus muscle surgery performed at the time of their Knapp operation. The horizontal surgery was performed in the same eye as the Knapp procedure in three cases, and in the contralateral eye in two cases. All three patients who had horizontal surgery in the same eye as the Knapp procedure achieved a postoperative horizontal alignment within $10^{\Delta}$ of orthophoria. Both patients who had concomitant horizontal rectus surgery in the contralateral eye had a postoperative horizontal deviation of $20^{\triangle}$ (one patient was undercorrected and one patient was overcorrected).

Information on postoperative fusional status was available for 16 patients and fusion was observed in seven patients. Five of these seven patients demonstrated evidence of fusion preoperatively. Two patients with postoperative fusion had long-term follow-up ( $>36$ months). The postoperative vertical drift for both of these patients was $5^{\Delta}$ and $6^{\Delta}$ respectively, and represented the two lowest drift magnitudes of the seven patients for whom long-term follow-up was available.

\section{Discussion}

The optimal surgical treatment for double elevator palsy remains controversial. Successful alignment has been achieved following partial tendon vertical transposition of the horizontal recti, ${ }^{7}$ conventional vertical rectus, and oblique surgery, ${ }^{4}$ the Callahan (modified Jensen) procedure, ${ }^{14}$ and both partial, ${ }^{816} 18$ and full ${ }^{69} 101516$ vertical tendon width transpositions of the horizontal recti. The largest series of patients undergoing surgery for DEP was reported by Dunlap $^{4}$ in 1952. Eighteen of 39 patients achieved a 'good or excellent' result, though categorisation of results was arbitrary. None of these patients were treated with the full-muscle transposition procedure subsequently popularised by Knapp. ${ }^{10}$

Thirteen to $73 \%$ of patients with DEP may develop secondary contracture of the inferior rectus in the paretic eye. ${ }^{611} 15^{17}$ Restriction can be detected by comparison of duction with version

Table 4 Correction of vertical deviation by Knapp procedure

\begin{tabular}{|c|c|c|c|}
\hline Author & $\begin{array}{l}\text { Number of } \\
\text { patients with } \\
\text { DEP }\end{array}$ & $\begin{array}{l}\text { Average vertical } \\
\text { deviation } \\
\text { corrected in } \\
\text { primary gaze } \\
(\triangle)\end{array}$ & Comments \\
\hline $\begin{array}{l}\text { Watson" } \\
\text { Knapp }\end{array}$ & $\begin{array}{r}2 \\
15\end{array}$ & $\begin{array}{l}30 \\
38\end{array}$ & $\begin{array}{l}\text { All had negative preoperative forced ductions. Nine } \\
\text { patients had primary DEP }\end{array}$ \\
\hline $\begin{array}{l}\text { Harley }{ }^{13} \\
\text { Cooper } \\
\text { Scott } \\
\text { Saroum- }\end{array}$ & $\begin{array}{l}4 \\
6 \\
5^{\star}\end{array}$ & $\begin{array}{l}25-40 \\
25 \\
37\end{array}$ & $\begin{array}{l}\text { One patient with positive forced ductions excluded } \\
1 / 6 \text { had simultaneous horizontal surgery } \\
\text { Prior IRc, no restriction at the time of the Knapp }\end{array}$ \\
\hline $\begin{array}{l}\text { Homsy' } \\
\text { Lee }^{17}\end{array}$ & $\begin{array}{r}2 \\
11\end{array}$ & $\begin{array}{l}29 \\
19 \\
23\end{array}$ & $\begin{array}{l}\text { Full Knapp } \\
\text { Knapp only } \\
\text { Knapp }+ \text { simultaneous IRc }\end{array}$ \\
\hline $\begin{array}{l}\text { Flicker }^{\text {ss }} \\
\text { Present study }\end{array}$ & $\begin{array}{l}15 \\
19\end{array}$ & $\begin{array}{l}21 \\
21 \\
38\end{array}$ & $\begin{array}{l}\text { Pre and post-op deviations not given } \\
\text { Knapp only } \\
\text { Prior IRc followed } \\
\text { by Knapp }\end{array}$ \\
\hline Dunlap ${ }^{1 x}$ & 2 & 35 & Patients graded supraplacement $\geq 10 \mathrm{~mm}$ \\
\hline
\end{tabular}

^ These patients are included in the present study movements, forced duction testing, '11 and vertical saccadic velocity studies. ${ }^{11}$ 12 If restriction is present it must be relieved by recession of the inferior rectus in order for a Knapp procedure to be successful. ${ }^{6131617}$ In some cases, the vertical deviation in primary gaze may be satisfactorily corrected by IRc alone. ${ }^{6}$ Simultaneous IRc and vertical transposition of both horizontal recti entails disruption of five of the anterior ciliary arteries - increasing the risk for postoperative anterior segment ischaemia. ${ }^{14}$ Consequently, a two-step approach, consisting of IRc followed by a Knapp procedure, has been advocated for the correction of vertical deviation in patients with evidence of restriction. ${ }^{6}$

Table 4 compares the average magnitude of vertical correction from the Knapp procedure observed in this study with that of nine previous reports. Our study represents the largest series of patients undergoing the Knapp procedure for the correction of DEP. The average magnitudes of correction in primary gaze in previous studies are similar to those found in this study. We found a statistically significant difference $(p<0.0017)$ in the magnitude of vertical correction in patients with an IRc performed prior to Knapp surgery $\left(38^{-}\right)$compared with those with no prior IRc $\left(21^{4}\right)$. Lee ${ }^{17}$ has reported equivalent magnitudes of vertical correction in patients undergoing a Knapp procedure with a simultaneous IRc. Knapp ${ }^{10}$ simultaneously recessed the inferior rectus in two patients without preoperative restriction, and postoperatively both patients obtained significant overcorrections in primary gaze. This suggests that prior IRc reduces the infraducting force of the inferior rectus, permitting a greater elevating effect from the superiorly transposed horizontal recti.

Patients who underwent a prior IRc were less likely to achieve successful vertical alignment than patients who did not undergo a prior IRc (Table 3). Patients having a prior IRc also had a greater magnitude of vertical change, though overcorrection was not significantly more frequent than undercorrection. This may be attributable to their larger magnitudes of preoperative vertical deviation.

Some authors advocate grading the magnitude of vertical displacement of the horizontal recti on the basis of the magnitude of the vertical deviation in primary gaze. ${ }^{16} 18$ Graded transpositions were not included in this study. In this study the amount of vertical correction in primary gaze obtained by the full Knapp procedure was independent of the size of the preoperative deviation and was not fully predictable for any given patient. However, the data in Figure 2 suggest that a partial tendon transposition could be considered if a patient has had a prior IRc and has less than 25 vertical deviation in primary gaze, or if the patient has not had a prior IRc, and the deviation in primary gaze is less than 10 .

The longitudinal data reported in this study suggest that the magnitude of vertical correction following a Knapp procedure increases with time. By comparison, Knapp, ${ }^{10}$ in his original series did not quantitate postoperative drift, however, he did note 'no deterioration in result' with an average follow-up of 4.5 years. The retrospective nature of our study limits the 


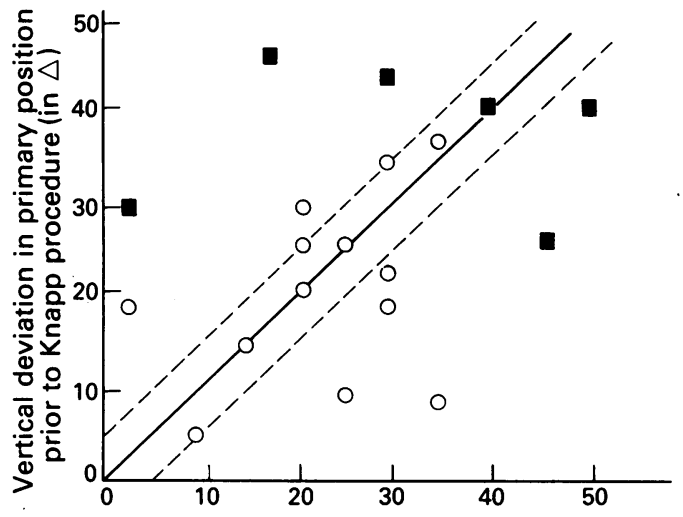

Magnitude of vertical change (in $\triangle$ )

Figure 2 Relationship of preoperative deviation to magnitude of change obtained by the Knapp procedure for each patient $\left(45^{\circ}\right.$ line [solid] indicates exact correction of the deviation; broken lines indicate $=1-5^{\Delta}$ of desired correction. $\mathrm{O} / \square=$ No prior/prior inferior rectus recession.

number and timing of intermediate follow-up visits available for analysis. However, the available data indicated that significant drift can occur at any time from 1 week to several years following surgery, and that the timing of this drift was variable. Regardless of which postoperative measurements were compared, all patients consistently drifted towards increased elevation over time. This has important clinical implications, as in the immediate postoperative period undercorrected patients can expect some drift toward an improved alignment, while overcorrected patients can expect to worsen.

The goal of most strabismus surgeries is to achieve postoperative fusion. Seven patients in this study had evidence of fusion following the Knapp procedure and five of these had preoperative fusion. All five had excellent alignment and no abnormal head position postoperatively. Fusion was first detected following Knapp surgery in the two other patients. Either these patients had gaze-dependent fusion preoperatively that was unrecognised because fusional testing was performed in only one position of gaze, or satisfactory postoperative alignment afforded these patients the opportunity to develop fusion. Achieving postoperative fusion may confer improved long-term stability of alignment. While only two patients with postoperative fusion had long-term follow-up, they drifted less than the other five patients for whom long-term follow-up was available.

In summary, the Knapp procedure can effectively improve or correct the hypotropia in patients with DEP and have an increased effect over time. The magnitude of correction is greater if a prior inferior rectus recession is performed, and is independent of the preoperative deviation.

This work was supported in part by an unrestricted grant from Research to Prevent Blindness. Dr Burke is the recipient of fellowship support from the TFC Frost Charitable Trust of the United Kingdom.

The authors would like to thank Randall S Condit, MD, for preliminary research, and C Kice Brown, MS, for biostatistical preliminary research, and C Kice Brown, MS,
assistance in the preparation of this manuscript.

1 Cooper EL, Greenspan J. Operation for double elevator paralysis. ' F Ped Ophthalmol Strabismus 1971; 8: 8-14

2 Jampel RS, Fells P. Monocular elevation paresis caused by a central nervous system lesion. Arch Ophthalmol 1968; 80: 45-57.

3 White JW. Paralysis of the superior rectus and the inferior oblique muscle in the same eye. Trans Sect Ophthalmol AMA $1941 ; 308-14$

4 Dunlap EA. Diagnosis and surgery of double elevator underaction. IV Congr Panamerican Oftal 1952; 3: 1554-66.

5 White JW. Paralysis of the superior rectus and the inferior oblique muscle of the same eye. Arch Ophthalmol 1942; 27: 366-71.

6 Scott WE, Jackson OB. Double elevator palsy: the significance of inferior rectus restriction. Am Orthop f 1977; 27: 5-10.

7 O'Conner R. Tendon transplantation in ocular-muscle paralysis. Am f Ophthalmol 1935; 18: 813-20.

8 Uribe LE. Muscle transplantation in ocular paralysis. $A m \mathcal{F}$ Ophthalmol 1968; 65: 600-7.

9 Watson AG. A new operation for double elevator paresis. Trans Can Ophthalmol Soc 1962; 25: 182-7.

10 Knapp P. The surgical treatment of double elevator paralysis. Trans Am Ophthalmol Soc 1969; 67: 304-23.

11 Metz HS. Double elevator palsy. F Ped Ophthalmol Strabismus 1981; 18: 31-5.

12 Metz HS. Double elevator palsy. Arch Ophthalmol 1979; 97 $901-3$

13 Harley RD. Complete tendon transplantation for ocular muscle paralysis. Ann Ophthalmol 1971; 3: 459-63.

14 Callahan M. Surgically mismanaged ptosis associated with double elevator palsy. Arch Ophthalmol 1981; 99: 108-12.

15 Ficker LA, Collin JRO, Lee JP. Management of ipsilateral icker LA, Collin JRO, Lee JP. Management of ipsilate
ptosis with hypotropia. Brf Ophthalmol 1986; 70: 732-6.

16 Barsoum-Homsy $M$. Congenital double elevator palsy. $\mathcal{F}$ Ped Ophthalmol Strabismus 1983; 20: 185-91.

17 Lee JP, Collin JRO, Timms C. Elevating the hypotropic globe. BrF Ophthalmol 1986; 70: 26-32.

18 Dunlap EA. Vertical displacement of horizontal recti. In Symposium on Strabismus: Transactions of the New Orleans Academy of Ophthalmology. St Louis: Mosby, 1971: 307-29. 